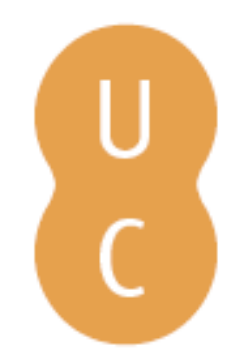

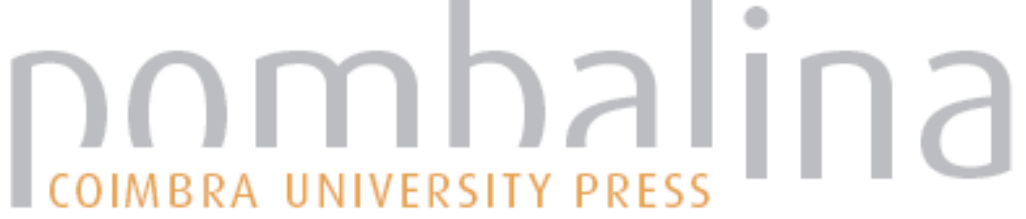

\section{Delitos sexuales en la Atenas clásica}
Autor(es):
Galaz, Mariateresa

Publicado por: Imprensa da Universidade de Coimbra

URL persistente:

URI:http://hdl.handle.net/10316.2/34650

DOI:

DOI:http://dx.doi.org/10.14195/978-989-26-0903-4_12

Accessed : $\quad$ 26-Apr-2023 06:44:53

A navegação consulta e descarregamento dos títulos inseridos nas Bibliotecas Digitais UC Digitalis, UC Pombalina e UC Impactum, pressupõem a aceitação plena e sem reservas dos Termos e Condições de Uso destas Bibliotecas Digitais, disponíveis em https://digitalis.uc.pt/pt-pt/termos.

Conforme exposto nos referidos Termos e Condições de Uso, o descarregamento de títulos de acesso restrito requer uma licença válida de autorização devendo o utilizador aceder ao(s) documento(s) a partir de um endereço de IP da instituição detentora da supramencionada licença.

Ao utilizador é apenas permitido o descarregamento para uso pessoal, pelo que o emprego do(s) título(s) descarregado(s) para outro fim, designadamente comercial, carece de autorização do respetivo autor ou editor da obra.

Na medida em que todas as obras da UC Digitalis se encontram protegidas pelo Código do Direito de Autor e Direitos Conexos e demais legislação aplicável, toda a cópia, parcial ou total, deste documento, nos casos em que é legalmente admitida, deverá conter ou fazer-se acompanhar por este aviso. 


\section{Delfim F. Leão - Livio Rossetti Maria do Céu G. Z. Fialho (eds.)}
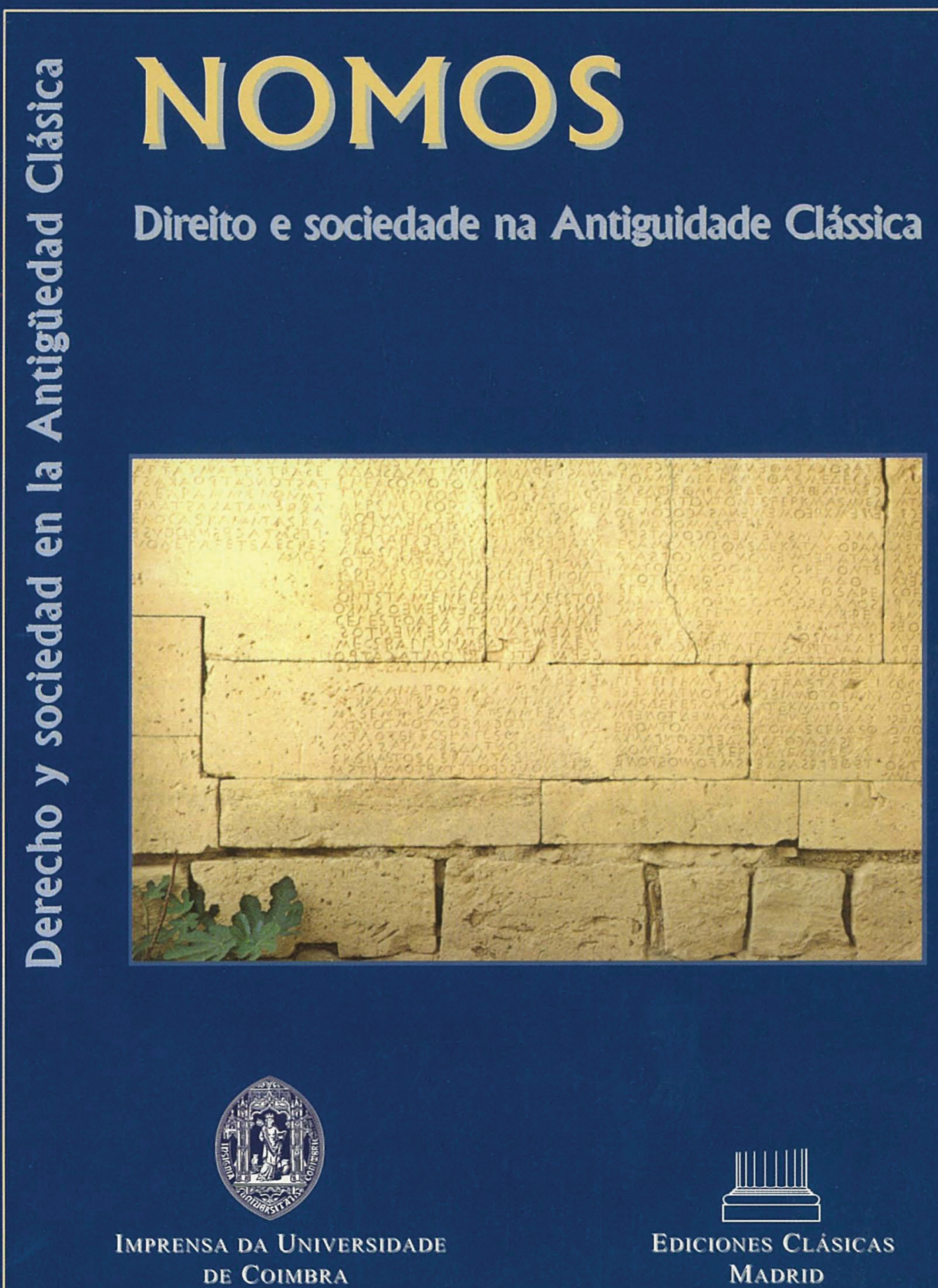

Ediciones Clásicas MADRID 


\title{
DELITOS SEXUALES EN LA ATENAS CLÁSICA
}

\author{
Mariateresa GALAZ
}

\begin{abstract}
"Sexual offences in classical Athens"
What I have tried to do in this article was to join a personal view of the problem with aspects of the debate towards the subject. In both cases, adultery and rape, there have been new interpretations which dismiss the old opinion, that while adultery was almost a matter of state, rape belonged to the private sphere and represented a minor fault in front of the law. As the spectrum widened, now there is a lack of trustful definitions and quite different positions about the state and the range of the laws. However, there are some trustable points from which one may depart to get a somewhat new point of view on both problems. What I do is confront the opinions with mine and among them so to confirm them or find a new one. Of course my aim was not to solve all polemical points, but to establish a reasonable ground for subsequent research.
\end{abstract}

\section{BREVE INTRODUCCIÓN}

A los años sesentas les debemos, quienes aún llegamos con poco retardo a la revelación del ' 68 , las revoluciones idealistas que a veces aterrizaban en la materialidad (i. e. Nicaragua, antes de que los héroes se corrompieran), y que otras veces se quedaron en el viaje psicodélico. De entre ellas, sin embargo, últimamente cobra importancia una muy peculiar, la liberación sexual, con una toma de conciencia más peculiar todavía: la de la decisión sobre el uso del propio cuerpo. Hija de tan inusitada liberación -pues por muy obvia que fuera al parecer nunca antes en la historia se había planteado una reivindicación parecida- fue la flamante nueva sexualidad que dio origen a los movimientos feminista y gay, y a los estudios de género. Y, para empezar, el concepto mismo, novedoso, de género, ya no de sexo, mucho más allá del listoncito azul o rosa en la cuna de un recién nacido.

Redundante resulta decir ahora que ambos movimientos y que los estudios mencionados integran parte de la agenda indispensable, a nivel mundial, de los derechos 
humanos. De entonces a la fecha se ha ido más lejos, con los derechos de la infancia, de los animales, del planeta y el concepto de tercera generación. Todos ellos de acuerdo con un espíritu de tolerancia que promueven, no obstante lo brutal de los tiempos, verdaderos militantes de la aventura vital, trátese de jóvenes, de intelectuales, de científicos, de trabajadores, de indígenas, muy rara vez de políticos.

Las expresiones de rebeldía sexual, aunque ahora sí definitivamente públicas, se dieron desde el comienzo de la civilización y diferentes culturas se comportaron más o menos tolerantes, o más o menos intolerantes respecto a ellas. Es un hecho, empero, que la actitud de las instituciones oficiales -el rey, el Estado o los órganos de poder, cualesquiera que éstos fuesen-, en ocasiones han sido responsables, al condenarlas de entrada, de causar una proporción importante de sufrimiento a los miembros descarriados de sus comunidades. Antes que pretendida moralidad, hoy el asunto es digno de estudios serios acerca del comportamiento humano ${ }^{1}$.

En este tono, hablar de delitos sexuales en la antigüedad presupondría desde especular si el concepto de delito utilizado actualmente correspondería al uso que nosotros damos a ciertas conductas antisociales, hasta concluir si no, las medicinas recetadas a tales conductas resultarían, bajo nuestra óptica, aún más antisociales; buenos ejemplos serían el homicidio justificado o la tortura pública infligidos al adúltero en Atenas clásica.

En suma, lo anterior no me sirve más que para enunciar la constante de parcialidad y de relatividad que implican estudios como éste y, por supuesto, para justificar mi visión, bastante modesta, en un campo en el que difícilmente puede decirse la última palabra.

\section{SOBRE LOS CONCEPTOS}

En su acepción más general, actualmente el vocablo delito denota una acción penada por las leyes por realizarse en perjuicio de alguien o por ser contraria a lo establecido por aquéllas ${ }^{2}$. También se define como culpa, crimen, infracción $n^{3}$. Se trata, en todo caso, de un comportamiento lesivo y antisocial ${ }^{4}$. En los códigos

${ }^{1}$ Cf. dos importantes ejemplos de una nueva postura que explicaría no sólo actitudes individuales sino movimientos sociales, tales como la homosexualidad, a partir de investigaciones recientes sobre anatomía y fisiología del cerebro humano: FisHer (1999) y SHLAIN (1998).

${ }^{2}$ Cf. Moliner (1984) s.v. delito. Del latín delictum, falta, error, delito, del participio pasivo neutro de delinquere, no cumplir (con el deber).

${ }^{3}$ Cf. CASAREs (1959) s.v. delito. En español desde el siglo XV (La Celestina, San Juan de la Cruz) significa culpa, crimen, quebrantamiento; posteriormente, en derecho, "cuerpo del delito: cosa en que o con que se ha cometido un delito o en la cual existen las señales de él, y acción u omisión voluntaria castigada por la ley con pena grave"; véase ALonso (1959) s.v. delito.

${ }^{4}$ Para el derecho penal, en efecto, "los delitos, en su mayoría, constituyen hechos que afectan directamente los bienes, los intereses o los derechos del ser humano (su vida, sus propiedades, su tranquilidad, su familia, etc.), pero no es únicamente la víctima del delito la que resulta dañada, puesto que la comisión de las infracciones penales causa también el quebrantamiento, en mayor o menor grado, 
modernos, además, se incluyen en esta categoría las conductas que violentan la persona o los derechos de otros en el terreno sexual, como pueden ser el estupro, la violación o el adulterio; en cuanto al incesto, éste se pena por la fuerte carga moral que comporta 5 . Todas ellas, en conjunto, más otras que no interesan aquí, se engloban normalmente bajo el rubro de delitos sexuales ${ }^{6}$.

En la Atenas clásica, por el contrario, los ahora llamados delitos sexuales estaban privados del estigma moral que indefectiblemente los caracterizó en épocas ulteriores ${ }^{7}$. Constituían más bien faltas de orden social -y sólo en este sentido podrían compartir el rasgo de conductas antisociales, como los delitos actuales-, aunque no estaban totalmente desprovistos de connotaciones morales que se manifestaban, sobre todo, en represalias de tipo religioso, específicamente contra la mujer adúltera. Con todo, no puede decirse que tales connotaciones hayan determinado su tratamiento por la ley, como en la época de la Santa Inquisición, sino más bien a la inver$\mathrm{sa}^{8}$. En mi opinión fueron, en todo caso, actitudes prácticas ligadas al contexto social y político las que determinaron de manera preponderante tanto los criterios para considerar la gravedad de tales delitos como su penalización. Por eso no debe causar extrañeza que delitos que en la actualidad caen en una esfera de suma gravedad, con connotaciones marcadamente sociales, y hasta políticas, como el estu-

de los derechos de la sociedad. Para proteger esos bienes contra todo tipo de ataque, el Estado ha elaborado una legislación especial en la que aparecen como delitos, los actos humanos por medio de los cuales pueden dañarse o ponerse en peligro diversos bienes jurídicos del hombre, atribuye, en cada caso, una pena que deberá ser aplicada al infractor": SOTO PÉREZ (2000) 90.

5 "Se castiga el incesto como delito, en defensa de la moralidad de la familia, prohibiendo relaciones sexuales que resultan inadmisibles en nuestro medio social". Cf. Soto PÉrEz (2000) 97. En Inglaterra, a partir de 1975, cuando se introduce legislativamente el divorcio, se incluye el incesto entre las causales: CHAVEZ AsCENCIO (1990) 421.

${ }^{6}$ En cuanto a la nomenclatura, ésta es relativa, y depende mucho de las tendencias y oscilaciones que muestren los diversos grupos sociales respecto de problemas concretos en la sociedad, lo cual obliga al Estado a modernizar la reglamentación misma, su denominación y las diversas instancias jurídicas donde ésta se cumple. Lo anterior es muy evidente en el caso de demandas de grupos en apariencia minoritarios como los ecologistas, los homosexuales o las prostitutas (que en México se denominan sexoservidoras), o de quienes luchan por los derechos humanos; en el caso de los delitos sexuales; por ejemplo, en México, a partir de las últimas reformas de 1991 al Código Penal del Distrito Federal, a los delitos antes llamados sexuales ahora se les denomina Delitos contra la libertad y el normal desarrollo psicosexual.

${ }^{7}$ Incluso en Grecia misma, como hace notar Gernet (1955) 53, cuando la idea de mancha moral impregna palabras como aiskhynein. Al respecto, cf. la posición de CANTARELLA (1991) 293: "Nor we can accept the hypothesis that the protected interest was the kyrios's interest in the decent sexual behaviour of the women under his kyrieia, as recently stated by Susan Guetel Cole (vid. Bibliografía). No estoy de acuerdo con P. G. McC. BRown (1991) 534 en el sentido de tomar como reflejo de los valores en época clásica el testimonio de la comedia de Menandro, cuyo personaje Gorgias, según el autor, "faithfully reflects a (not very surprising) view which was held at the time in Athens" y, por lo tanto, como apoyo para refutar los argumentos de Eufileto en Lys. I, dada la distancia tanto cronológica como ideológica entre ambos autores y, presumiblemente, entre sus respectivos públicos.

${ }^{8}$ Como en general "coinciden" en señalar, desde perspectivas algo diversas, tanto FoxHALL (1991) 299 ss como CAREY (1995) 416-17. 
pro o la violación ${ }^{9}$, fuesen susceptibles de repararse a un nivel interpersonal, mientras que la argumentación en casos específicos del delito de adulterio -Lisias I, Sobre el asesinato de Eratóstenes y el discurso fragmentado de Hipérides 2, En favor de Licofrón-, cuyo ámbito es hoy sin duda individual, resultara creíble para su auditorio en sus tonalidades de casi crimen de Estado ${ }^{10}$.

\section{EL PROBLEMA}

Al contrario de la situación actual, donde los delitos sexuales están bien definidos como delitos y perfectamente encasillados como sexuales -incluso tratándose de delitos que técnicamente lo son por su grado de tentativa, como el acoso sexual, diferente del abuso sexual-, en la antigüedad griega no hay tanta certeza, al menos no para nosotros. Hablo de la antigüedad griega y no romana, puesto que, al no existir propiamente jurisprudencia, el derecho griego no está exento en ningún momento de lugares obscuros en la ley, de ambigüedades y, sobre todo, de interpretaciones ${ }^{11}$.

En este sentido, algunos términos de las leyes se prestan a análisis de detalles muy técnicos, como el de CANTARELLA (1991) 291-92 -refiriéndose al discurso I de Lisias- al significado de flagrante delicto, tradicionalmente identificado en griego como ep'autophoro, con una acepción mucho más amplia, pero más literalmente expresado, según la autora, por ep'ergo y por arthra en arthrois ${ }^{12}$ que ella equipara

\footnotetext{
${ }^{9}$ Me parece que es el caso, por ejemplo, de las llamadas "muertas de Juárez", las alrededor de 5,000 mujeres masacradas -entre aproximadamente 4,500 desaparecidas y 267 aparecidas muertas, identificadas o no- que han sido atacadas sexualmente, torturadas y mutiladas en México en la ciudad fronteriza de Juárez desde 1993 hasta la fecha, y que han merecido la atención de al menos media docena de libros, así como del documental "Señorita extraviada", de Raquel Portillo, sin que las investigaciones policíacas logren resolver satisfactoriamente ni un solo caso. Se ha planteado con mucha claridad que la situación económica de las víctimas es de pobreza, ya que casi todas son obreras de las maquiladoras, lo cual contribuye tanto a la corrupción de las autoridades como a la impunidad; la situación parece trascender el ámbito penal y llegar a las altas esferas políticas del país ya que, según testimonios de una obra reciente, Harvest of women, de Diana Washington, periodista norteamericana, es muy probable que se trate de una red constituida por miembros de familias importantes de la clase política y empresarial, quienes tendrían la responsabilidad de al menos un número relevante de tales homicidios.

${ }^{10}$ De hecho, en eso consiste la acusación de Hipérides 2 que acepta el tribunal por eisangelia, poceso de alta traición contra el Estado.

${ }^{11}$ Esta situación ya fue acertadamente notada por HARRIS (1990) 373, n. 12, en relación con la defensa que hace COLE del discurso de Eufileto en Lisias I, así como por CAREY (1995) 407, quien, pese a admitir un cierto tipo de jurisprudencia, afirma que: "Their jurisprudence is therefore not objective but designed to produce specific effects as part of the process of persuasion".

${ }^{12}$ Según PaOli (1950) 145, el solo hecho de que el adúltero viole el domicilio ya constituye delito, y la flagrancia puede darse sorprendiendo al adúltero arthra en arthrois ekhon o por su sola presencia en la casa después de cometido el adulterio.
} 
a situaciones legales tanto en derecho romano como en el derecho italiano actual y que, siguiendo esta línea, cambiaría esencialmente el carácter de la argumentación de Eufileto; en efecto, al serle imposible a éste demostrar que la postura de los adúlteros en el acto sexual era exactamente arthra en arthois perdería validez su reclamo. Lo anterior es descartado por FoxHALl (1991) 299, quien hace notar lo tardío de la fuente (Luciano) y su inviabilidad para acreditar que arthra en arthrois ya tuviera un uso tan altamente especializado en Atenas arcaica o clásica. Del mismo modo, las observaciones de CAREY (1995) 409, n.10 respecto a la indefinición de la ley -pues no especifica si en el momento de sorprender al adúltero la relación sexual debe estar en curso o consumada, ni si la pareja debe estar desnuda o medio vestida, y se atiene al sentido común para inferir que un hombre a solas con una mujer decente está por tener, o tiene, una relación sexual- echarían por tierra las especulaciones de CANTARELLA.

Contrariamente a esta tendencia a "profesionalizar" la legislación y a los juzgadores griegos -a imagen de los romanos- va el comentario de MACDOwell (1976) 24: "Athenian law was not drafted by professional lawyers using terminology which only they understood; it was made by the citizens of Athens in their own language for their own use, and an Athenian finding the verb hybrizein in a law would take it to mean just what it normally meant in ordinary speech."

Otro grave problema con las leyes es que, como hace notar CAREY (1995) 407, pese a las lagunas de que adolecemos en cuestión de evidencias para el corpus jurídico general ateniense, tenemos una impresión falsa de coherencia: "Legislative measures belonging to different periods are likely to present themselves as a result of an integrate design rather than the product of accretion." El resultado inmediato en los tribunales de esta falsa visión de coherencia y continuidad era que, al servirse los litigantes de diferentes leyes de distintos momentos históricos -cada cual con sus necesidades y propósitos legales de lo más diverso-, sobrevenían confusiones y contradicciones en donde cada logógrafo hacía valer tanto su conocimiento del sistema como su habilidad para presentar sus demandas de manera congruente, dejando a los jueces la tarea de interpretarlas. Tarea ardua y difícil, si recordamos las características del procedimiento en Atenas, puesto que el tiempo de reflexión y de análisis con que éstos contaban para emitir su veredicto era prácticamente nulo, por lo que, a un nivel pragmático, lo que dejaba mella en ellos no era la claridad y consistencia de los argumentos, sino la impresión de claridad y consistencia, inclinándose entonces más por argumentos convincentes acerca de verdades o de hechos jurídicos que por la demostración de tales verdades o hechos.

Un breve ejemplo de tal coexistencia de leyes de diferente origen y época, así como de las inclinaciones de los jueces a valorar lo aparente nos lo da HARRISON (1968) 34, cuando, refiriéndose a una situación concreta del delito de adulterio, comenta que, en el supuesto caso de que se permitiese matar al adúltero y no al violador, debió haber sido imposible para un marido que se hiciera justicia por su propia mano demostrar que la esposa había sido seducida y no violada, mientras que 
"to establish this by argument and witnesses in a legal process would have been perfectly possible."

Además de la falta de definición de situaciones legales determinadas, y de la ambigüedad de las leyes, para nosotros se da el problema de la pertinencia y viabilidad de las fuentes. Por tratarse de conductas penadas que normalmente se resolvían ante los tribunales, el grueso de nuestras fuentes son los discursos logográficos de fines del siglo V y principios del IV. Sin embargo, dada la naturaleza del procedimiento jurídico en Atenas, tales discursos constituían "pruebas" en sí mismos, y así contenían los elementos para que los jueces establecieran criterios y tomaran decisiones. Es evidente que, como dice CAREY (ib.), "our sources distort", porque tal era la naturaleza misma de ese tipo de fuentes, que también había expuesto BATEMAN (1958) $277 \mathrm{ss}^{13} \mathrm{y}$, últimamente, HARRIs (1990) 370-75, entre otros.

Por último, a riesgo de sonar una obviedad, cabe señalar el escollo cultural, porque pese a que actualmente tenemos un panorama mucho más amplio de la antigüedad griega que hace treinta años, cuando nuevos estudios acerca de la ley y de la mujer griega comenzaron a desplazar a muchos mitos forjados y sostenidos con anterioridad por los estudiosos, aún no existe un criterio que logre unificar, o inclusive elaborar conceptos más claros y precisos de lo que constituía la moikheia en Atenas y para los atenienses, o dónde se delimitaban seducción y violación o, como ya hizo notar con mucha oportunidad HARRISON (1997) 197, hasta qué punto el sexo socialmente aceptado en Grecia comprendía no sexo consensual y no consensual para la mujer, sino sólo formas de sexo no consensual, y (198) hasta qué punto en patrones de este tipo", was all sex rape, or was there no such thing at all?"

\section{III.1. La polémica: adulterio}

El problema comienza desde las definiciones. Un término que ocasiona divergencias entre los estudiosos es el griego moikheia, traducido generalmente por "adulterio". Pero moikheia es, en Atenas, más que eso: "any sexual intercourse between an Athenian citizen and the wife, daughter, sister, mother or concubine of another citizen, unless the woman is a prostitute"14. La definición anterior tiene su origen en una ley que se remonta a Dracón y que aparece en Demóstenes 23. 53 (y 55), Contra Aristócrates:

${ }^{13}$ A propósito de un libro de Erik WoLf, Griechische Rechtsdenken, de 1950-6, que no me ha sido posible consultar.

${ }^{14}$ Cf. CANTARella (1991) 289 ss. Allí mismo la autora refuta a COHEN (1991) 100 ss, quien rechaza esta visión ampliada de moikheia en Atenas, frente a un esquema general en varias culturas mediterráneas donde el adulterio "centrally involves a voluntary violation of the marital bonds", o donde la seducción parece restringirse a las "solteras" vírgenes y el adulterio identificarse más con mujeres casadas. Del mismo modo, FoxHaLl (1991) 297-98. 
"Si alguien mata [a otro] involuntariamente durante las competencias atléticas, o con violencia en la calle, o accidentalmente en la guerra, o [al sorprenderlo] con su esposa, o con su madre, o con su hermana, o con su hija, o con la concubina que tiene [para procrear] hijos legítimos, por estas causas no será desterrado por homicidio." 15

Para CAREY (1995) 408 ss, en la ley citada no hay claridad acerca de si la situación se refiere a adulterio o a violación, ya que, en su opinión, aquélla adolece de la falla de no establecer la naturaleza del cargo, si por violencia o por persuasión, por lo que podría aplicarse indistintamente a uno u otro caso, y usarse en la defensa tanto de un violador como de un seductor ${ }^{16}$. De hecho, el elemento más importante que distingue a ambas conductas delictivas, la violencia ${ }^{17}$, no se encuentra contemplada por la ley. Pero en textos del período clásico, es el adulterio el que conlleva persuasión.

En la ley anterior aparece la lista de mujeres "por las cuales está permitido matar"18. Es claro que en una sociedad esclavista, donde los amos podían disponer libremente del cuerpo de sus esclavos, las relaciones con los otros grupos -metecos y libertos- estaban vedadas ${ }^{19}$, y la prostitución se ejercía con bastante libertad, generalmente por hombres o mujeres de la categoría de los libertos, sólo se consideraba que había adulterio cuando se daba entre miembros del grupo dominante, los ciudadanos, y con respecto a una mujer legítimamente casada (gamete) o de algún modo comprometida en una unión similar al matrimonio (pallake o concubina), cuyo fin fuera la procreación de hijos legítimos, o con alguna de las mujeres incluidas en la lista anterior, ciudadanas sujetas a la kyrieia o tutela de un pariente varón cercano. El discurso del pseudo Demóstenes 59, Contra Neera, documenta el caso

${ }^{15}$ [Trad. M. Galaz] A pesar de compartir la tesis de la protección al linaje en Atenas (cf. infra, esta misma sección), no coincido con el manejo parcial que de esta ley hace OGDEN (1997) 26-7, ni con su interpretación de que "this clause probable did aim primarily at the protección of bloodlines" pues, como Euflileto, le confiere a un fragmento de la ley una intención que, como un todo, no tiene. Su opinión de que "the Athenian lawcode as a whole did at least permit the killing of adulterers, seducers and rapists; the general subject of the law which this permission was given was less important", refleja una visión confusa, pues mientras considera un "lawcode" a leyes emitidas aisladamente, en tiempos y circunstancias y con objetivos diferentes, mutila una ley que habla de los casos en los que el homicidio es justificable y hasta disculpable, tratándose todos ellos de circunstancias accidentales, agrupables por su carácter ocasional y, posiblemente, excepcional. Cf. HARRIS (1990) 371: "All the law states is that the man who catches someone having intercourse with his wife and kills him cannot be condemned for murder. The law about the Aeropagus does not inflict the death penalty on adulterers; it only specifies what constitutes lawful homicide".

${ }^{16}$ Seguramente un duende de la imprenta substrajo las palabras "o con su madre" tanto del griego como de la traducción de la mencionada ley que reproduce en su artículo CAREY.

${ }^{17}$ Cf. infra, III. 2.

${ }^{18}$ Lisias I. 32-33.

${ }^{19}$ Sobre todo a partir de la ley del 451/50, propuesta por Pericles con el fin de restringir el número de ciudadanos, así como de golpear a la nobleza aplicando graves penalidades a los matrimonios mixtos, ya que hasta entonces había sido una tradición de la aristocracia el contraer matrimonio con nobles extranjeros. 
de un hombre en principio acusado de moikheia con una mujer no casada, supuesta hija del demandante.

Ahora bien, si la fidelidad por parte de la mujer llegó casi a institucionalizarse, el hombre tenía completa libertad, e incluso el modo de vida más común lo estimulaba para que sostuviera relaciones extramatrimoniales, ya que, por principio, le era lícito sostener trato sexual con varias mujeres a la $\mathrm{vez}^{20}$, sin que se tomase en cuenta el estado y categoría de ellas, excepciones hechas de los casos mencionados con anterioridad por Demóstenes 23. Así, mientras la fidelidad femenina llega a significar una especie de certificado de legitimidad para los hijos, ante la ley era indiferente el estado civil del sujeto implicado en la relación de adulterio ${ }^{21}$.

Para la situación llana expuesta arriba ha habido diversas interpretaciones de corte jurídico y sociológico. Según PAOLi (1950) 126 ss, 139 ss, en la comisión del delito de adulterio un elemento es necesario: la violación del propio domicilio, ya que ello constituye una ofensa (hybris) al oikos. Así, GERNET (1979, 1a. ed. 1955) 54-55 piensa que el adulterio es, esencialmente, "une violation a l' autonomie d' une maison". El hecho de que al adúltero sorprendido flagrante delicto se le puedan aplicar sanciones de manera directa por parte del marido, sin intervención de los órganos de justicia, "sono la sopravvivenza di un piú antico diritto e risalgono a un periodo storico nel quale la sovranitá familiare e la sovranitá della pólis (ristretta alla organizzazione della guerra) si esercitavano in sfere distinte e independenti (151)". En esta línea sigue CAREY (1995) 416: "Hence the requirement that a married woman caught in adultery must be divorced by his husband, The legislation on moicheia is thus a piece with the protection of orphans and epikleroi, and the duty of the archon to take care of oikoi in danger of dying out. It reflects the interest of the state in the preservation of the oikos. There was more broadly an issue of citizenship".

La ley anterior, de Demóstenes 23, es mencionada en Lisias 1.30, donde se habla de ella como la ley del antiguo tribunal del Aerópago, y varios autores coinciden en calificarla como la ley de homicidio justificado (phonos dikaios):

"Habéis oído, señores: al mismo tribunal del Aerópago, al cual ha sido concedido tanto entre nosotros como en el tiempo de nuestros padres el juzgar las causas de asesinato, se le dice explícitamente que no reconozca como asesinato [la acción] de aquél que, habiendo sorprendido a un adúltero con su propia mujer, haya tomado esta venganza. Y a tal punto el legislador consideró que esto era justo en el caso de las

\footnotetext{
${ }^{20}$ No me refiero aquí a la posibilidad de que también pudieran sostener relaciones con otros hombres; primero, porque ello no afecta para nada la consideración del adulterio y, segundo, porque la homosexualidad en sí implicaba otra categoría de la cultura masculina, plenamente aristocrática, la del amante-preceptor del amado, fenómeno que no tiene nada que ver con la visión cotidiana de la homosexualidad, que a un nivel popular era despreciada (cf., por ejemplo, Lisias 3, Contra Simón).

${ }^{21}$ Cf. también CHRIST (1989) 522-24.
} 
mujeres casadas, que inclusive en el caso de las concubinas, dignas de menor estimación, estableció la misma pena." 22

Sin embargo, en Lisias 1. 28 se menciona otra ley que ha sido identificada de manera diversa, ya que para alguno sería la ley concerniente al procedimiento de la apagoghé en el caso de los moikhoi: PAOLI (1950); mientras que otro descarta esa posibilidad en favor de una auténtica ley sobre el adulterio: CAREY (1995). En este punto hay una amplia discusión sobre la categoría de los moikhoi como kakourgoi -y, por lo tanto, como sujetos a un juicio de kakourgon apagoge ante los Once-, interpretación que hizo por primera vez PAOLI (1950) 153 ss, a partir de la mención de Aristóteles en la Constitución de Atenas 52.1, donde se describe el procedimiento de apagoge contra varios tipos de delincuentes -entre quienes no se menciona a los moikhoi-, a los que tampoco se clasifica como kakourgoi, y la de Esquines 1.901, Contra Timarco, donde enmarca a los moikhoi en la categoría de kakourgoi y describe el procedimiento sin mencionar para nada la apagoge. Así pues, tanto por Esquines como por Aristóteles conocemos los detalles del procedimiento, que consistía en un arresto sumario y, si el delincuente confesaba (homologein), la ejecución era inmediata; si negaba su crimen, era enviado a los tribunales para ser juzgado, de donde, si los jueces lo absolvían, salía libre; pero de resultar culpable, también sufría la pena capital; allí, a decir de Esquines, "la verdad sale a la luz a partir de las probabilidades." ${ }^{23}$ PAOLI justifica la inferencia moikhoi = kakourgoi $>$ apagoge. En ese mismo sentido se manifiesta HANSEN $(1976,1981)$, a quien siguen Cohen (1984, 1991), Cantarella (1991) y, aparentemente, Todd (1995); pero es refutado por GAGARIN (1979), cuya postura recoge HARRIS (1990).

De acuerdo con lo anterior, COHEN (1991) hace una lectura distinta de las leyes, con la que concuerda CANTARELLA (1991), en el sentido de interpretar que, en 1. 28 -comentada en 1. 29- Eufileto se refiere, primero, a una ley que concierne a los adúlteros en calidad de kakourgoi, cosa que COHEN infiere de 1.29, donde aquél narra su encuentro con el adúltero y Eratóstenes confiesa reiteradamente su delito (homologei adikein) ${ }^{24}$; y que luego, en 1.30 , a partir del comentario que Eufileto hace allí mismo, se ve que se trata de la ley de phonos dikaios (= Demóstenes 23. 53).

Finalmente, sin entrar propiamente en la polémica, CAREY (1995) recoge la observación de HARRIS (377) en el sentido de que cuando aparece citado el procedimiento de apagoge nunca se presentan ejemplos de moikhoi; considera, así, que de tratarse de la ley sobre apagoge kakourgon ésta significaría un fuerte impedimento al derecho del marido a ejecutar por su propia mano al adúltero, por lo que

\footnotetext{
${ }^{22}$ Lisias, 1. 30-31. Las traducciones de este discurso son de Paola Vianello De Córdova (cf. Bibliografía).

${ }^{23}$ [Trad. M. Galaz: ...heurisketai de he aletheia ek ton eikoton.]

${ }^{24} \mathrm{La}$ reiteración se entiende de los imperfectos en griego.
} 
era poco probable que Eufileto la hubiese citado, y descarta entonces esa posibilidad para inclinarse por una ley específica sobre el adulterio ${ }^{25}$.

"No discutía, señores, sino que reconocía haber actuado $\mathrm{ma}^{26}$, y rogaba y suplicaba que no se le matara, y estaba dispuesto a pagar dinero. Pero yo no acepté su avalúo, sino que estimaba que la ley de la ciudad tenía más autoridad, y tomé esta venganza que vosotros, por considerar que es la más justa, decretasteis para quienes cometen tales acciones." ${ }^{27}$

A partir de esta distinción -en realidad un juicio valorativo- que hace Eufileto entre el adúltero y el violador, el testimonio de Lisias en general fue tomado por los estudiosos como la evidencia de que, efectivamente, en Atenas la violación era menor en gravedad que el adulterio, puesto casi a la altura de crimen de Estado:

“...consideró [el legislador] que los violadores eran dignos de una pena menor que los seductores; pues contra éstos sentenció la muerte, y para aquéllos estableció el doble del daño, considerando que quienes llevan a cabo su acción con violencia, son odiados por los violentados, mientras que los seductores a tal punto corrompen sus almas, que hacen a las mujeres ajenas más familiares a ellos que a sus esposos, y toda la casa queda en su poder, y los hijos no se sabe de quién son, si de los esposos o de los amantes. ${ }^{228}$

Parecía, entonces, que más que en la esfera moral, el adulterio estaba inmerso en la esfera social de la polis, mientras que la violación quedaba reducida a un asunto meramente privado, y ello se reflejaba en lo leve de la penalidad impuesta a ella, penalidad que, como se ha visto últimamente, sin que se le atribuya a la violación el papel social del adulterio en la polis, era equiparable a la de éste. Es evidente que el monopolio que ejerció el testimonio de Lisias, aceptado sin más, sin aplicarle el criterio que toda fuente de naturaleza retórica exige, contribuyó a desarrollar la idea del adulterio como crimen de Estado y de la violación como un fenómeno natural, visto casi con complacencia por la comunidad, sobre todo teniendo a la mano la comedia latina y lo que hay de la nueva, tradicionalmente utilizadas como testimonios de la Grecia clásica - tradición que, a mi parecer, habría que revisar. Esta interpretación, que resultó bastante fantasiosa y que en la actualidad ha sido dejada a un lado, fue revisada por BATEMAN (1958), señalada por VIANELLO (1980), y luego acuciosamente rebatida por HARRIS $(1990)^{29}$, con cuya posición en general concuerdan

\footnotetext{
${ }^{25}$ No tendría nada que ver con la ley que en pseudo Demóstenes se intitula "Ley de adulterio" (cf. infra, en esta misma sección) que, como señala TODD (1995) 278, n.21, se encuentra en el manuscrito seguramente como conjetura de un escriba tardío y no forma parte del discurso.

${ }^{26}$.En griego, homologei adikein; el vocablo homologein es utilizado como término técnico tanto por Esquines 1. 90-1, como por Aristóteles en la Constitución de Atenas 52.1, en el sentido de "confesar."

${ }^{27}$ Ibid., 29.

${ }^{28}$ Id. 1. 33. Cf. lo mismo en Jenofonte, Hierón, 3.6.

${ }^{29}$ Quiero mencionar la pertinencia y seguimiento lógico del análisis de este autor sobre la argumentación de Eufileto en Lisias 1, aunque bastante acre en su polémica con Cole (ib.); sin embargo,
} 
Cantarella (1991), Carey (1995) y, parcialmente, Foxhall (1991). A propósito de esto, me suscita una inquietud el comentario de BATEMAN (1958) 284 de que "Lysias did have a high regard for the values of the law and the proper administration of justice. But at the same time he has that Athenian disrespect for the specific law, which Aristophanes caricatures in the figure of Strepsiades." A tal actitud doble se refiere en seguida como "...this tension or dialectic between dikaiosyne (in its fullest meaning for the city-state) and to sympheron..." En mi opinión, el asunto no era de moralidad, sino de pragmatismo: con moralidad sola no hubiera habido abogados. La retórica (estrategias retóricas) entra en el pragmatismo profesional del logógrafo Lisias como to sympheron ${ }^{30}$.

Por otra parte, considero que el viejo argumento de que el adulterio pone en entredicho la legitimidad de los hijos no puede ser echada al cesto de papeles tan fácilmente. En Atenas, a diferencia de Esparta, el proyecto democrático hace prevalecer a un grupo social estableciendo, al mismo tiempo, medidas para proteger su reproducción y su nitidez; no a otro propósito obedece una ley (tan racista e intolerante) como la del 451/50 que, ojo, no impide las relaciones sexuales entre ciudadanos y extranjeras/ extranjeros, puesto que la prostitución es negocio floreciente entre los extranjeros y extranjeras que llegan a Atenas; ni siquiera el derecho de procrear hijos sin derechos, bastardos (nothoi), como Pericles el pequeño, que por obra y gracia del demos adquirió la ciudadanía y se dio el lujo, después, de demandar a otros por usurpación de ésta. Lo que tal ley impide es el matrimonio legítimo, léase

me parece contradictorio el que caiga en juicios valorativos que, primero, en el caso de Eufileto como personaje lo hacen incurrir en la exageración de presentarlo constantemente como un sofista o, por lo menos, como "sofístico", no obstante su afirmación inicial de que "Lysias did not write a legal textbook for his client; he wrote a speech for a man who was on trial for murder and had to convince the court of his innocence" (371) -sobre este punto, cf. PARADISO (1995) 106-; y, segundo, en la parte final de su exposición (375) lo hacen contradecirse de nuevo, ya que si los jueces, al identificarse como hombres con Eufileto, encontraron "seductores" sus argumentos contra los adúlteros -independientemente de que eso diese a Lisias muchas posibilidades de votos a favor de su cliente, entonces este discurso si es una fuente confiable para las actitudes sociales, al contrario de lo que HARRIs afirma un momento antes sobre el valor testimonial de los oradores en general.

${ }^{30}$ Acerca de algunas observaciones de BATEMAN (284, n.27) sobre las tácticas acostumbradas de Lisias en el discurso 1, "designed to shift the attention of the dikasts from. the actual charge which seems to have been laid -the way, not the fact, in which Euphiletus killed Eratosthenes was ilegal", no estoy de acuerdo. Me parece que el hecho fue ilegal puesto que había otras alternativas (una suma de compensación o un juicio). Pero Lisias no estaba construyendo su caso; éste ya existía con ciertas características y su deber como abogado era encontrar las estrategias pertinentes que ayudasen a su cliente. Así que, en mi opinión, desde el principio este caso trata no con justicia (dikaiosyne), sino con argumentos tomados de "lo útil" (to sympheron). Creo que es en este mismo sentido que en el discurso 1 , y en los otros dos discursos que analiza BATEMAN, el estudioso puede observar atinadamente que "Lysias deals correctly with the laws which bear on his case. His treatment of most of the laws which he cites in these speeches has a common element: it is fundamentally sophistical" (277). Por otra parte, cf. Gould (1980) 47: "He [Eufileto] lay stress on the (apparent) normality of relations between he and his wife; whether he is telling the truth or not it is irrelevant to us. All we need bear in mind is that Euphileto's domestic life is intended to sound normal". 
la posibilidad de procrear hijos cuyo origen racial y social fuese incierto; hijos que heredarían la categoría social y política de sus padres -esto es, el control político de la ciudad, el patrimonio material de la familia y el culto a los antepasados. Por su antigüedad y la diferencia de contexto en el que, al menos la ley de Demóstenes 23 fue creada, es muy improbable que originalmente haya sido pensada para apuntalar la protección del linaje o la certificación de la legitimidad de los hijos; pero indudablemente fue actualizada y, según CAREY (1995) 412-13, endurecida por Solón, dándole un cariz de mayor gravedad que las referentes a la violencia sexual. El hecho de que, como señala CAREY, fuera de la ley de homicidio justificado no haya textos acerca del derecho de matar a un violador, mientras que sí los hay en el caso del adúltero, es señal de esa situación. Para este autor, la gravedad de las penas que sufre la pareja de adúlteros es una prueba de que este delito, finalmente, sí era considerado de más relevancia para la polis que la violación.

En torno a este asunto, cabe recordar el señalamiento de PAOLI (1958) 151 sobre las dos esferas de impartición de justicia independientes: la familiar/ individual, correspondiente a un estadio histórico arcaico, y la social/ pública, donde coexisten el derecho familiar y el derecho de la polis. En este mismo sentido van VIANELLO (1980) CXLIII ${ }^{31}$ y CANTARELLA (1991) 293, para quien el derecho del marido de matar (¿y de torturar? cf. pseudo Demóstenes 66) al adúltero se trata de una especie de concesión que hace el nuevo derecho institucionalizado de la polis a las antiguas atribuciones del jefe de familia, con el fin de que se respete la nueva ley de homicidio ${ }^{32}$.

Contemporáneas en la Atenas clásica las dos vías -tanto en el caso del adulterio como en el de la violación-, para el marido engañado existía, en el caso de sorprender al adúltero flagrante delicto, la alternativa entre el homicidio y el rescate del moikhos mediante una compensación como la que ofrece Eratóstenes y que Eufileto rechaza, teniendo entonces el marido la posibilidad de secuestrar al adúltero hasta recibir la suma acordada Precisamente en torno a un caso de este tipo gira el argumento del pseudo Demóstenes 59. 66 Contra Neera, donde el presunto moikhos inicia una acusación pública (graphe adikos eirkhthenai hos moikhos) contra el supuesto padre de la mujer por haber sido secuestrado indebidamente como adúltero:

${ }^{31}$ Cf. n. al párrafo 32: "El argumento que Eufileto desprende de aquella relación -vale decir, que la seducción es más grave que la violencia- es especioso (aunque, en última instancia, puede no ser falso). En efecto, la diversidad de las penas previstas en los casos de violencia y de seducción depende de la diferente antigüedad de las dos leyes más que de la voluntad de los legisladores. La ley draconiana sobre el adulterio debía ser más antigua que la otra, ya que descansaba en el principio gentilicio de la venganza privada; mientras que la otra apunta hacia una época que buscaba la composición de los pleitos con la mediación de las instituciones públicas". Evidentemente, al hablar de "violencia" aquí VIANELLO se refiere a la violación.

${ }^{32}$ No voy a discutir aquí la finalidad de legalización de la prole que para CANTARELLA implica dicha ley, en dirección a comprender el concepto de moicheia en su acepción amplia (y tradicional), en contraposición a COHEN (1991); fue refutada por FoXHALl (1991) 298-99 en el sentido de la inadecuación temporal del argumento. 
"Si alguien es secuestrado indebidamente como adúltero, que demande en un proceso público ante los thesmothetas que ha sido secuestrado indebidamente; y si logra que se condene al que lo secuestró y que se determine que indebidamente ha habido confabulación en su contra, que sea absuelto y que sus fiadores sean liberados de todo compromiso; y si se determina que es un adúltero, [la ley] ordena que sea entregado a los fiadores de su acusador, para que éste, ante el tribunal, lo maltrate como quiera, [excepto herirlo] con un puñal ${ }^{33}$, como a un adúltero"34.

En este punto hay también una fuerte discusión sobre el significado y los alcances de la última frase, tanto por el hecho mismo de que se permita al acusador abusar físicamente de su demandado, lo cual constituiría, evidentemente, un acto de hybris en contra de este último -cf. CAREY (1995) 414: "...under the nomos moikheias one citizen was granted the right to commit hybris againsta another"-, como por el tipo de abuso al que se le expone. Para PAOLI (1950) 149-51, el hecho de que se especifique que el maltrato será aneu enkheiridiou, "non escludesse la morte, ma limitasse i mezzi di esecuzione in chi uccideva l'adultero sorpreso i flagrante o confesso. Ció confermerebbe che il moikhos andava giustiziato mediante bastonatura". El estudioso enumera una serie de torturas que supone eran infligidas al adúltero en Atenas, pero casi todas sus fuentes son tardías o romanas. En cambio, a partir de Aristófanes $^{35}$, al que COHEN (1985) en general descalifica como fuente, dice MACDOWELL (1978) 124 que "favourite kinds of treatment for a seducer were to push radishes up his anus and to pull out his pubic hair". Contrariamente a COLE (1984), para quien la frase aneu enkheiridiou garantiza que no haya muerte como penalidad de la graphe moikheias, HARRISON (1968), HARRIS (1990) y CAREY (1995) la consideran factible.

Además de este "ajuste de cuentas" privado de la ejecución inmediata del adúltero sorprendido flagrante delicto, o de la posibilidad de obtener de él un rescate, el marido podía seguir el camino de los tribunales en la corte de los thesmothetai, y promover varios tipos de juicios: público, como la graphe moikheias, o bien privados, indistintamente una dike hybreos o una dike biaion. La pena, en la primera clase de proceso, era la muerte, una vez que se hubiese probado que la mujer había sido seducida. En los otros dos tipos de juicio, la pena era una multa. Plutarco menciona someramente la cantidad de cien dracmas a que el adúltero estaba sujeto ${ }^{36}$. De cualquier modo, se ignora en qué casos o por qué motivos se recurría a una clase de proceso o a la otra ${ }^{37}$.

${ }^{33}$ Según HARRISON (1968) 33, "the sword".

${ }^{34}$ [Traducción de M. Galaz]

${ }^{35}$ Nubes, 1083; Pluto, 168.

${ }^{36}$ Cf. Plutarco, Solón, 23.

${ }^{37}$ Cf. HARrison (1968) 33. Sin embargo, cf. la interesante interpretación de PARAdISO (1995) 102 ss, donde retoma la tesis de HALPERIN (1990) 88-112 sobre "el cuerpo democrático", e inserta en su contexto el uso de los tres tipos de procesos. 
Por lo que respecta a las sanciones hacia los cónyuges, no existe el concepto, ni jurídico ni moral, del perdón. Así, la ley señala que al descubrirse un caso de adulterio sobreviene automáticamente el divorcio, y amenaza al marido con atimia si no lleva a efecto en seguida la disolución del matrimonio. En cuanto al asunto mencionado de pasada por Esquines 1. 107, sobre los presuntos casos de adulterio que cometiera Timarco siendo gobernador de Andros, y que, a decir del litigante, los maridos preferían callar, para FOXHALL (1991) 303 entran como situaciones verosímiles aceptables por los jueces atenienses en el sentido de no exponer a los esposos a que se viera su falta de autoridad en sus respectivas casas. De cualquier modo, por tratarse de una situación fuera de Atenas, no podrían tomarse como un testimonio de ella al pie de la letra. He aquí la ley referente al punto, como aparece en el pseudo Demóstenes 87:

"LEY DE ADULTERIO: Cuando se haya sorprendido al adúltero, no se permitirá al que lo sorprendió convivir con su mujer y, si convive [con ella], que sea privado de sus derechos ciudadanos. Tampoco se permitirá participar en los sacrificios públicos a la mujer con la cual se haya sorprendido al adúltero; y si participa, que sufra impunemente lo que sea, salvo la muerte"38.

La mujer, entonces, una vez que había sido reputada como adúltera, sufría represalias que cambiaban su vida totalmente, desde lo personal y familiar hasta lo social. Además del divorcio y, por consiguiente, de la privación de los hijos, recibía lo que ahora llamaríamos "muerte civil", ya que se le excluía automáticamente de las únicas instancias por las que se insertaba en la vida social y pública de la ciudad, que eran las celebraciones religiosas, además de reglamentársele una serie de prohibiciones que la dejaban casi en calidad de paria por su indefensión respecto al resto de la comunidad ${ }^{39}$ :

"Solón, el legislador más prestigiado, escribió antiguamente y con solemnidad sobre la buena conducta de las mujeres. A la mujer sorprendida con un adúltero no le permite usar adornos, ni asistir a los sacrificios públicos, con el fin de que no corrompa a las mujeres honestas al relacionarse con ellas. Y si asiste [a los sacrificios] o usa adornos, [el legislador] ordena al primero que la encuentre que le desgarre los vestidos y que le arranque los adornos y que la golpee, sin llegar a matarla o a mutilarla, deshonrando a esta clase de mujer y preparándole una vida insoportable" ${ }^{" 40}$.

Hay un silencio total de las fuentes respecto a la situación de una mujer adúltera después de su divorcio ${ }^{41}$. HARRISON (1968) 36 hace referencia a la posibilidad de

\footnotetext{
${ }^{38}$ [Trad. M. Galaz]

${ }^{39}$ Para PARAdiso (1995) 98, se trata de "un'atimia que mirava ad umiliarla, a privarla del rispetto e dell'invulnerabilitá di cui aveva goduto come moglie (o madre, sorella ecc.) di un cittadino". Cf. infra, III.2 La polémica: violación.

${ }^{40}$ Esquines 1. 183. [Trad M. Galaz]

${ }^{41}$ Aunque la práctica de un segundo matrimonio tanto en hombres como en mujeres era común, según nos dejan ver las propias fuentes, y después de un divorcio o al quedar en la viudez, podemos
} 
que una mujer que fuese calificada como adúltera y deseara probar lo contrario, podía promover, por medio de su kyrios o de cualquier otro ciudadano, una graphe hybreos, que, empero, no le garantizaba ser escuchada en primera instancia por el tribunal, pero no da referencias a este respecto. Por otra parte, ignoramos si se dio la circunstancia de que un adúltero tuviese hijos propios dentro de una casa ajena, y si tal circunstancia le hubiera permitido apoderarse de los bienes de ésta, en caso de muerte del marido ${ }^{42}$, al menos tratándose de una epikleros o heredera universal. De cualquier modo, en el pasaje de Lisias 1 donde se habla de la diferencia entre adúlteros y violadores, y en otros lugares ${ }^{43}$, está claramente reflejado el temor del titular del oikos de que éste pueda estar influido por extraños.

\section{III.2. La pólémica: violación}

Acerca de los términos que determinan una situación de violación, tampoco están definidos ${ }^{44}$, como, durante años, tampoco fue contemplado tal delito en su justa dimensión. En efecto, a partir de la citada comparación de Eufileto, en Lisias 1 , entre los adúlteros y los violadores, se aceptó una interpretación de que la violación era una especie de "delito menor" ${ }^{45}$ que podía ser reparado a nivel interpersonal, y de que en Atenas carecía de una reprobación, ya no moral, sino siquiera social, porque desde sus orígenes había estado relacionada con el desarrollo mismo de la comunidad. En esta línea, el hecho de que se le asociara con el rapto primitivo, cuyas reminiscencias aún se encontraban en la ceremonia nupcial (gamelia), hace decir a GERNET (1979, 1a. ed 1955) 53, que "qui viole violent, il ne déshonore pas".

especular sobre la prácticamente imposibilidad de que un ciudadano tomara en matrimonio a una mujer repudiada ya por adulterio, puesto que la convivencia con ella había quedado prohibida para el propio marido bajo pena de atimia. Tampoco es probable que se hiciera concubina (pallake) "formal", por así decirlo, de un ciudadano, ya que esta categoría gozaba de cierta respetabilidad. Lo que me lleva a especular, como únicas opciones, que se dedicara a la prostitución, o que sostuviera relaciones informales con individuos de otro grupo social, como libertos o esclavos.

${ }^{42}$ Véase el caso opuesto, el de un marido que vive en concubinato con una mujer de status poco claro, probablemente una liberta, y cuyos supuestos hijos ponen en peligro a los herederos legítimos, en Iseo 6, Sobre la herencia de Filoctemón.

${ }^{43} \mathrm{Cf}$. Iseo 1 , Sobre la herencia de Cleónimo, 10, donde éste, soltero y sin hijos, teme dejar, aunque sea temporalmente, sus asuntos en manos del tutor de sus sobrinos - su propio cuñado- con quien había tenido conflictos: "Pues consideraba que sería terrible dejar a su mayor enemigo en calidad de tutor (epitropon) de sus familiares y de administrador (kyrion) de sus bienes, así como que le hiciese las honras fúnebres, mientras nosotros alcanzábamos la pubertad, aquél con quien en vida había tenido diferencias." [Trad. M. Galaz]

${ }^{44} \mathrm{El}$ que no se aporte una definición clara de lo que significa "rape" (violación) en términos de la antigüedad es un reproche que constantemente hace HARRIS (1997) a los colaboradores del volumen Rape in Antiquity (cf. Bibliografía, DEACY-PIERCE, 1997).

${ }^{45} \mathrm{Cf}$. HARRISON (1968) 34: "While we can accept the broad point that, paradoxically, seduction was more severely dealt with than rape, we cannot be certain of the details..." 
Además, ante la casi ausencia de testimonios de la época clásica, y ante la conversión del fenómeno social en un tópico, más o menos popular, de la comedia nueva y de la comedia latina, se ha dado por supuesto -y así se ha utilizado- que como fuente éste género es a la violación lo que un Lisias 1 es al adulterio -con todas las objeciones que, como hemos visto, se le puedan presentar ${ }^{46}$.

Lamentablemente, como en el caso de la moikheia, en griego tampoco hay precisión en la utilización de los términos. Cole (1984) 98 ss señala que no existe un término explícito para "violación" en el sentido de "sexual intercourse committed by force", aunque remite a expresiones que, en ciertas circunstancias, denotan lo mismo. Sobre los vocablos que se relacionan, describen o definen una violación, COLE (1984) 98-9 hace un inventario donde aparecen las familias de bia (violencia física) y de hybris (soberbia; ultraje; violencia) ${ }^{47}$, pero también de harpazo (prender, someter a alguien). Sin embargo, prevalece la ambigüedad, ya que todos esos términos y sus parientes lingüísticos pueden emplearse también en otros contextos con un significado distinto. También da cuenta de la polémica existente a partir del artículo de MACDoweLL (1976) sobre una delimitación y un intento de definición del concepto de hybris ${ }^{48}$.

En cuanto a la búsqueda de una definición, CoHEN (1990) 100 da un elemento para sentar, al menos, ciertos límites. Cuando habla del adulterio, dice: "The element of voluntariness distinguishes it from rape," y amplía (100, n.1): "All ancient legal systems ditinguish rape and adultery according to the woman's consent and the man's use of force..." En este sentido concuerda CAREY (1995) 408, quien, además de la violencia en la violación (contrariamente a la moikheia -en este caso entendida como adulterio-, que implica persuasión) añade que mientras la moikheia tiene que ver siempre con mujeres, la violación incluye mujeres y hombres; aunque este último hecho está presente en la ley de la hybris ${ }^{49}$, y en todos $1 \operatorname{lados}^{50}$, creo que no se había señalado explícitamente como marcador de las diferencias entre ambos delitos.

${ }^{46}$ Cf. íbid. 19 y n. 2: HARRISON especula acerca del caso de un soltero que hubiese violado a una joven y fuese obligado a casarse con ella, recibiéndola sin dote para librarse de la muerte a manos de su padre (de haber sido sorprendido en casa de ella flagrante delicto, y por lo tanto caer en la categoría de moikhos), y acepta que la casi totalidad de las evidencias son "from Roman comedy and writers on rhetoric of the Roman period".

${ }^{47}$ En el análisis que hace MACDowell (1976), a partir de todo tipo de fuentes literarias, encuentra siete campos semánticos bien definidos para hybris y algunas subdivisiones, con distintos significados, algunos de los cuales detecta PARADISO (1995) 108-9, al hablar de la "violencia consensual".

${ }^{48}$ Cf. COLE (1984) 99, n. 13 ha sintetizado bien la discusión, y apunta que mientras MACDowell (1976) "emphasizes the attitude of the offender", FisHER $(1976,1979)$ "concentrates, more correctly, on the effects of hybris on the victim"; Y GAGARIN (1979) "points out that in Rhet. 1373b28-74a17 Aristotle indicates that the definition of hybris depends not so much on the attitude of the offender, but on his intent". Habría que añadir a esta lista a CAIRNS (1996), quien replica un libro reciente de FisHER, de 1992 -que infortunadamente no pude consultar-y actualiza el estado de la cuestión.

${ }^{49}$ Cf. Demóstetes 21. 47, Contra Midias.

${ }^{50}$ Como en la ley de Gortina, por ejemplo. Cf. también Dover (1978). 
Por su parte, PARADISO (1995) 97 ss, busca aclarar con una mayor sutileza los diferentes aspectos de la violación "-la violenza bruta, la vergogna impostá, l'intenzione di oltraggio- dando vita a rappresentazioni differenti dello stesso evento". Este panorama me parece novedoso, ya que inserta ese paso intermedio entre la seducción del adulterio (consensual) y la violencia de la violación (no consensual) que es, en términos de un código penal moderno, el estupro, mismo que difiere de la violación, precisamente, en que logra su objetivo no mediante la violencia, sino mediante el engaño. Para los griegos, esto equivaldría también a la persuasión, a la que entonces, en mi opinión, se podría considerar en términos de gradación, o como la presenta esta estudiosa, de matices. Así, PARADISO ve en el léxico un reflejo de esas diferencias: "Il vocabulario stesso della violenza carnale sottolinea talvolta la sopraffazione fisica-questo accade per esempio con i verbi biasthai e biazesthai- talvolta invece esalta le consegueze psicologiche subite dalla vittima, la vergogna determinata dal'oltraggio: é il caso di hybrizein, ma sopratutto di aiskhynein o anche di atimazein, verbo preso di prestito dalla sfera politica che definisce metaforicamente la diminuzione inflitta alla donna violentata".

En todo caso, para CAREY (409) tiene razón HARRISON (1968) 34 cuando, al analizar los testimonios de Plutarco, Solón 23 y de Lisias 1 señala, en el caso del moikhos sorprendido flagrante delicto, la incapacidad de dilucidar ante los jueces si una mujer fue violada o seducida, lo que no nos extraña en vista de las sutilezas que en sí conlleva el suceso mismo. Tal vez por aquí cabe ubicar la cuestión planteada por otro HARRISON (1997) 198 en torno a si el sexo era o no consensual en todos los casos, donde residiria el problema de fondo: si existía la violación o no ${ }^{51}$.

Por lo que toca a las leyes sobre la violación, éstas se encuentran en Plutarco, Solón 23. 1-2 y en Lisias 1. 32. Para Cole (1984) se trata de dos versiones de la misma ley. En cuanto a Hipérides 1, Contra Licofrón, según Cole su testimonio es incoherente con el de de Solón 23.1-2. En efecto, dice sobre la ley Plutarco:

“En general, parece que las leyes de Solón sobre las mujeres son muy raras. Pues mientras que [aquel] permite al que sorprenda a un adúltero que lo mate, si alguien se lleva a una mujer libre y la viola, ordenó de castigo cien dracmas. Y si la prostituye, 20 dracmas, excepto aquéllas que "manifiestamente se venden", es decir, las cortesanas.; pues éstas abiertamente rondan [buscando] a los que les pagan. E inclusive, no permite vender ni a la hija ni dar a la hermana, excepto a la muchacha que, sin estar casada, sea sorprendida con un hombre" 52 .

En cambio, la ley de fines del siglo V citada por Lisias 1. 32 dice así:

${ }^{51}$ Cf. al final de III. El problema. De aquí necesariamente se salta al problema de la sexualidad entre los griegos, y de las relaciones interpersonales en los diferentes tipos de parejas, incluido el matrimonio, que ha sido tratado por diversos autores. Cf. DOver (1978) Y HuMPHREYs (1983).

${ }^{52}$ [Trad. M. Galaz] 
“...[la ley] ordena que si uno con violencia ofende ${ }^{53}$ a un hombre libre o a un muchacho, pague doble del daño; y si a una mujer de aquellas junto a las cuales es lícito matar [sc. esposas legítimas o concubinas], se sujete a lo mismo. Así, señores, consideró que los violadores eran dignos de una pena menor que los seductores; pues contra éstos sentenció la muerte, y para aquéllos estableció el doble del daño..."

La impresión de Plutarco, expresada en seguida, es que dichas leyes no son unitarias, puesto que a un delito lo castigan con severidad extrema -matar al adúltero y vender a la hija soltera-, mientras que a otro lo ven de manera indulgente -pagar sólo una multa en el caso de una violación-. Para Cole (1984) 100 ss estos dos testimonios son diferentes versiones de una misma ley sobre asalto sexual, y plantea una diferencia con la moikheia: que esta última tenía lugar dentro de la casa, mientras que la violación se llevaba a cabo afuera, hecho que enfatiza a partir de un testimonio de Menandro (101); en mi opinión, la fuente no es especialmente atingente, por tratarse de un tópico literario y tardío, y además no se apoya en ningún otro testimonio que indique esa hipótesis. Su reconstrucción de una supuesta "ley original" sobre asalto sexual, basada esencialmente en conjeturas, fue rechazada por HARRIS (1990) 372-73.

La situación de una mujer de quien se había abusado sexualmente cambiaba de manera radical si el hecho no se había dado con violencia, sino que se trataba de estupro, porque ello suponía que entre la mujer y el violador había una cierta complicidad; en este caso podía emprenderse una acusación seria de adulterio. La esposa misma, si en realidad había sido violada, corría siempre el peligro de ser considerada adúltera; y según HARRISON (1968) 36, "it would seem that the victim of rape was liable to just the same treatment as she would have been a willing cooperador in the adultery, "aunque no se apoya con referencia alguna en este sentido. Para CAREY (1995) la situación social y moral de la mujer violada implica términos como aiskhynein y entra en el ámbito de la pérdida de timé. Aunque, a diferencia de la mujer adúltera, la víctima de violación no está condenada al repudio del marido (divorcio) ni a sanciones sociomorales como aquélla; según PARADISO (1995) 98, sufre "solo un oltraggio, vale a dire una degradazione non giustificata da alcuna colpa o reato, un atimia ingiustificata. É questo il significato dell'oltraggio, della hybris: la sua gratuitá".

\section{IV. ¿Hay solución?}

En este punto cabe hacer una observación: en el caso del adulterio la víctima, el cónyuge "ofendido" y, hablando más ampliamente, de la moikheia, es el hombre de la casa, el kyrios de la mujer, sea su marido, su padre, su hijo, su hermano o su amante $^{54}$. Si la moikheia envuelve una violación, la mujer es una víctima aleatoria:

\footnotetext{
${ }^{53}$ Perífrasis de "viola": Vianello (1980) CXLIII. 32.

${ }^{54}$ Como ya lo notó Foxhall (1991) 302.
} 
la ofensa va contra su kyrios, contra su oikos y, en última instancia, a decir de PARADISO (1995) 98-9, contra el pacto de justicia entre los miembros de una comunidad; en el caso de la hybris erotica, no conlleva tanto la humillación sexual, "quanto di umliazione sociale e morale, cioé di potere".

Me parece que aquí se encuentra una clave del problema. En efecto, desde el punto de vista del poder, ambos delitos - sin considerar el estupro, que tradicionalmente cae en la seducción y, por lo tanto, en el adulterio-, son atentatorios contra la autoridad de ese kyrios. Dice FoxHALl (1991) 299 ss: "A very important source of men's power and authority as heads of households was that (ideally, at least) they could control the sexual activities of other household members (including animals and slaves), but that they themselves were autonomous and no one else could dictate their sexual activities". En una paráfrasis de su argumentación, mencionaré que relaciona lo anterior con la que llama una de las ideologías prevalecientes de la vida social de Atenas, según la cual el hombre era dueño de sus propios deseos sexuales, mientras que la mujer era juguete de los suyos y, por lo tanto, necesitaba de control externo por parte de hombres responsables. Siguiendo esta lógica, una falla en ese terreno implicaba una falla a nivel de la autoridad del hombre en el oikos y, como efecto dominó, acarrearía al afectado una cadena de problemas como el desprestigio, tal vez el divorcio -opción menos deseable aún si la mujer tenía dinero y él debía devolver la dote-, quizá la humillación de ser ofendido por un hombre de un status superior, como es el caso en Lisias 1. Según esta visión, la mujer juega un doble papel: protagónico -aunque FoxHaLl no emplea el término- en la moikheia, y como víctima en la violación. En este punto difiere la opinión de PARADISO (1995) 107 que, en su interpretación, para la ley aún en el adulterio "la donna sia sempre oggetto pasivo, anche quando attivamente consenziente, di seduzione"

De lo visto con anterioridad podrían hacerse algunas reconsideraciones: en primer lugar que, como ya varios estudiosos han señalado, el corpus jurídico ateniense estaba constituido por leyes de diversas épocas que respondieron a condiciones sociales y políticas específicas, para las que el o los legisladores en turno aplicaron penalidades específicas. Por supuesto, seguían criterios prácticos -lo que los oradores y todo el mundo denomina "la intención" del legislador- aplicables a ese momento histórico. Como las leyes no se derogaban, ni tampoco se agruparon o se reunieron en códigos, como harían después los romanos, sino que continuamente surgían otras nuevas, en diferentes condiciones y con criterios diversos, pasado su momento resultaban ya inaplicables o extemporáneas u obsoletas o, por lo menos,

\footnotetext{
${ }^{55}$ Me parece que en sus consideraciones finales -después de un análisis muy preciso y linealPARADISO pierde consistencia, pues se limita a confrontar fuentes de diferentes épocas para afirmar la gravedad de la violación, que no me parecen allí tan definitorias; por cuanto al problema del "consenso" de la mujer, es interesante puesto que lo equipara a la gravedad de las sanciones para la mujer en ambos delitos, pero con la afirmación anterior más bien obscurece el asunto. Sobre el tema final, el concepto de la "violencia consensual", basado en algunos de los significados que detecta MACDOWELL (1976) me parece una lástima que no lo haya planteado de manera más amplia.
} 
conflictivas. Su coexistencia resulta, como ya se ha visto en un principio, en ambigüedades y contradicciones que hacen por lo menos decir de algunas de ellas a Plutarco que son "raras" (Solón 23, atopoi).

Además, según el procedimiento, toda ley estaba sujeta a su caso y no a la inver$\mathrm{sa}^{56}$. Es decir, la ley se invocaba en la demanda de ese caso específico y era en función del caso que tanto demandante como demandado estructuraban sus respectivas estrategias en el litigio. A continuación, se insertaba en cierto momento de sus discursos, si era oportuna, y pasaba a formar parte de un tejido argumentativo donde el pilar más fuerte ya no era la letra de la ley en sí, sino la lectura que cada quien hiciera de ella, desde la que proponía o insinuaba el logógrafo, hasta la que en lo individual hacía cada uno de los jueces, y todos ellos en su conjunto ${ }^{57}$. Más que un prurito por la precisión jurídica, entonces, lo funcional era el manejo de topoi en los que tales jueces vieran reflejados sus valores y sus inquietudes, y era fundamental, por ello, el uso de argumentos ideológicos. Ni siquiera en situaciones excepcionales como la especie de "ajuste de cuentas" que constituía el homicidio del moikhos (en cualquiera de las modalidades de moikheia), y que en cierto momento podía justificarse mediante una determinada ley, su asesino estaba exento de ser llevado al tribunal y enfrentar el riesgo de pagar penas graves por su acto, como demuestra Eufileto en Lisias 1. En esas circunstancias, la legislación con mucha frecuencia estaba al servicio del trabajo, totalmente pragmático, del abogado, consistente en maquillar con recursos retóricos y con leyes las coyunturas específicas en las que su cliente había cometido el delito. La referencia de Eufileto al desplante dramático de cuando exclama, ante un -creo- aterrorizado Eratóstenes: "No soy yo quien va a matarte, sino la ley de la ciudad, que tú transgrediste, estimándola en menos que los placeres, y preferiste cometer una falta tan grave hacia mi mujer y mis hijos, que obedecer a las leyes y ser honesto" 58 , nos plantea la invocación a una ley que le permite matar al adúltero porque simultáneamente está violando otras que dan garantías a su rival de conservar la vida, ya mediante un rescate, ya mediante un juicio más o menos equitativo (epieikes).

En segundo lugar, en el caso de la moikheia, puede observarse que, más que delimitar la naturaleza o el tipo de delito sexual, al parecer enmarcaba la red de perso-

${ }^{56} \mathrm{Cf}$. GAGARIN (1979) 317-18: “...the claim that the prosecutor is employing the wrong procedure may have been fairly common in Athenian courts ..."

${ }^{57}$ Cf. GAGARIN (1979) 323: "To the extent that the laws did not cover certain areas or certain special situations, they allowed for exceptions to the rule." En mi opinión, tales excepciones constituirían una parte de la epieikeia en los tribunales -en el sentido de la "equidad" del derecho inglés y norteamericano, no como "imparcialidad"-, y la otra residiría en la libertad de criterios que tenían los jueces para interpretar la voluntad del legislador, ya fuese más cerca de lo justo o de lo útil; cf. LAWLESS (1991). Pongo como ejemplo el caso de un arbitraje en Iseo 2.30: "Ellos nos dijeron que si les dejábamos que determinaran lo justo (ta dikaia), no podrían arbitrar...pero que si permitíamos que se decidieran por lo más conveniente (ta sympheronta) para todos, que lo harían". [Trad. M. Galaz] Sobre la relación de la epieikeia con lo justo y lo útil, cf. Aristóteles, Topica, 141a 15 ss.

${ }^{58}$ Cf. Lisias 1. 26. 
nas en o con las que tal delito se cumplía. Que es de naturaleza sexual, no hay ninguna duda; pero carece de la especificidad que da la nomenclatura a los delitos sexuales en la actualidad, y ello parece deberse a los mitos y prejuicios relativos a las mujeres de los que hablaba un poco más arriba Foxhall (1991). Si una mujer era tan pusilánime como para no hacerse cargo ni de sus propios impulsos sexuales, ¿cómo podría, entonces, marcarse un límite drástico entre lo que constituía un asalto sexual, con lujo de violencia; o una fuerte agresión psicológica que hiciera casi innecesaria la violencia en el momento del acto sexual; o una "caída" de tipo moral debida a la ignorancia o a la ingenuidad o a la capacidad para dejarse engañar de la mujer? ¿O la franca voluntad de la mujer de Eufileto, que consiente en que se hostigue al bebé para tener un pretexto para salir de la habitación -a sabiendas de que su amante ya llegó-; que frente a su marido finge que juega, y en la realidad lo encierra bajo llave; que se maquilla estando de luto y que se hace amiga de la madre de su amante? Los delitos que para nosotros oscilan entre la violación, el estupro, el abuso sexual, el acoso sexual, la corrupción de menores y que tienen -cada unocomo espejo en la legislación su equivalente figura jurídica, no susceptible de confundirse con la de los demás, al parecer en Atenas estaban comprendidos, en buena parte, dentro de la moikheia, al menos tratándose de mujeres libres y ciudadanas. Y era precisamente esta última categoría la que le daba a la moikheia su gravedad frente a la ley.

El hecho de que una mujer adquiera el control de su propia sexualidad y de que le haya quitado ese control a su kyrios, de víctima -en una situación de violaciónse vuelve, en mi opinión, cómplice y protagonista. Esta situación explicaría para FoXHALl (1991) 302-3 el requerimiento de un divorcio inmediato, porque "she is effectively removed from the community of obedient women." En la descripción de Lisias y de Jenofonte, son los adúlteros quienes hacen a las mujeres más familiares hacia ellos que hacia sus maridos, pero en el trasfondo una mujer que tome el control de su propia sexualidad (arrebatándoselo al kyrios, según FoxHALL), está tomando a la vez sus propias decisiones, que trascienden su ámbito usual de acción; está, de algún modo, "empoderándose". De objeto pasivo, sujeto a las decisiones de un kyrios, se vuelve cómplice del moikhos y, peor aún, protagonista de su propia historia. Por ello, a esas mujeres hay que alejarlas de los demás, y aquí viene bien la ley atribuida a Solón y que cita Esquines en 1. 183 en la que se le aísla como contaminada para que no "corrompa" a las mujeres "honestas", es decir, para que su mal ejemplo no cunda en la comunidad. Al tomar la mujer una decisión de ese tamaño, que trasciende su propio ámbito de decisiones en el interior del oikos, y que tiene consecuencias al exterior para su marido, para su oikos, y para los hijos, cuyo origen pone en entredicho, pasa a arrogarse una capacidad que de suyo ni ella ni el grupo de mujeres del que forma parte tiene, y así se convierte en una especie de outsider de su comunidad o, más aún, cuando es virtualmente expulsada de ella, en una paria.

Esa situación de que no pueda tomar decisiones sobre su propio cuerpo, como no puede disponer de su propiedad, que es administrada por el kyrios, la pone, en 
cierto modo, casi a la altura de los esclavos, ya que su cuerpo, en realidad, no es de ella. El hecho de que, pese a la gravísima penalidad impuesta a las mujeres adúlteras, hubiese adulterio, implica que quizá era un medio de escape a la rigidez de la vida social de las mujeres ciudadanas, aun cuando hubiese un alto grado de libertad y de capacidad de decisión de aquéllas dentro del oikos ${ }^{59}$. Pese a la configuración retórica de su mujer como villana, Eufileto deja ver que, en realidad, fue persuadida por Eratóstenes. Si pensamos que la edad de matrimonio de las jóvenes atenienses oscilaba entre los doce y los quince años, y que esta mujer había permanecido un tiempo sin hijos -seguramente el lapso del embarazo-, y que el bebé era aún lactante y debió haber tenido unos meses, la edad de ella no debió sobrepasar los diecisiete años. Infortunada, en su primera aventura fue traicionada y sorprendida; su rival, en cambio, la dueña de la esclava anciana que la delata, debió ser mayor y con más experiencia, al grado de que se atreve a denunciarla jugando con la carta de casi ponerse ella misma al descubierto. ¿Cuántas mujeres, como ellas, vivirían una doble vida, cuidándose de los riesgos, y formando parte todavía de la comunidad de mujeres "honestas", mientras sus maridos repartían su tiempo entre las tareas del campo, los negocios, la vida política y la vida social propia de los ciudadanos?

En mi opinión, el problema aún está irresuelto, y como veta dista mucho de agotarse. Pero me parece que una vía alterna para ayudar a clarificarlo es el tipo de análisis como el de Foxhall, que lo aborda una vez más desde otro punto de vista. Por mi parte, me hago cargo de que en este escrito quedan muchos puntos en suspenso, más los que, seguramente, serán inciertos o erróneos, y me disculpo por las importantes aportaciones que ya no tuve oportunidad de ver. En todo caso, espero que tenga algún valor como un modesto intento de rastrear cómo enfrentaban los atenienses situaciones que, todavía ahora $-\mathrm{o}$ tal vez más que nunca ${ }^{60}$ ponen al filo de la navaja el cotidiano fluir de la convivencia humana.

\footnotetext{
${ }^{59}$ Hechos que me parece que ha demostrado sobradamente FoxHall (1989) con anterioridad.

${ }^{60}$ Pongo, como ejemplo, la fuerte polémica que durante los últimos años ha habido en México sobre el caso de Paulina, niña de condición económica pobre, que a los doce años fue atacada sexualmente en su propia cama por un delincuente drogado que amagó con un cuchillo a su familia. Como carecía de recursos para procurarse un aborto clandestino, solicitó que se lo hicieran en un hospital público, amparada por el Código Penal, que lo autoriza en esas circunstancias. Su solicitud fue reiteradamente denegada por las autoridades del estado, de ideología de derecha. Como el caso se volvió asunto público, el gobierno estatal se comprometió a ayudarle a seguir sus estudios y en la manutención de su hijo. Actualmente, Paulina vive con su madre y el niño - de poco más de cuatro años-, trabaja para mantenerlos y no recibe ninguna ayuda; culpa a las autoridades de "haber arruinado su vida" por no permitir que se cumplieran las leyes que en su caso autorizaban la interrupción del embarazo por ser éste producto de una violación.
} 


\section{BIBLIOGRAFÍA}

\section{EDICIONES Y COMENTARIOS}

Lisias: Sobre el asesinato de Eratóstenes. Defensa. Introducción, traducción y notas de Paola Vianello De Córdova (México, 1980).

Lysias: Selected Speeches. Edited by C. CAREY (Cambridge, 1989).

\section{ESTUDIOS}

Alonso, Martín: Enciclopedia del idioma (México, 1958).

Brown, P. G. McC.: "Athenian Attitudes to Rape and Seduction: The Evidence of Menander, Dyskolos 289-293”, CQ 41 (1991) 533-34.

CAIRnS, Douglas L.: "Hybris, Dishonour and Thinking Big", JHS 116 (1996) 1-32.

Cantarella, Eva: "Moicheia. Reconsidering a problem", in Symposium 1990: papers on

Greek and Hellenistic legal History, ed, M. GAGARIN (Cologne, 1991), 289-96.

CAREY, C.: "Rape and Adultery in Athenian Law", CQ 45 (1995) 407-417.

CASARES, Julio: Diccionario ideológico de la lengua española (Barcelona, 1959).

ChÁvez Ascencio, Manuel F.: La familia en el derecho. Relaciones jurídicas conyugales (México, 1990).

CHrist, Matthew R., "Legal self-help on Private Property in Classical Athens", AJP 119.4 (1998) 522-545.

CoHEn, David: Law, Sexuality and Society. The enforcement of morals in classical Athens (Cambridge, 1991).

CoLE, Susan Guetel: "Greek Sanctions against Sexual Assault", CP 79 (1984) 97-113.

DEACY, Susan and Karen F. PIERCE, eds, Rape in Antiquity (London, 1997).

Dover, K. J.: Greek Homosexuality (Cambridge, 1978).

Fisher, Helen: El primer sexo (Madrid, 2003; $1^{\mathrm{a}}$ ed. 1999).

FisHER, N. R. E.: "Hybris and Dishonour: I", G\&R 23 (1976) 177-93.

— "Hybris and Dishonour: II", G\&R 26 (1979) 33-47.

FoxHALL, Lin: "Household, Gender and Property in Classical Athens", CQ 39 (1989) 22-44.

— "Response to Eva Cantarella": Symposium 1990: papers on Greek and Hellenistic legal History, ed. M. GAGARIN (Cologne, 1991), 297-304.

GaGARIN, Michael: "The Athenian Law against Hybris", in Arktouros. Hellenic Studies presented to Bernard W. Knox on the occasion of his 65th birthday, eds. Glen W. Bowersock, Walter Burkert, Michael C. J. Putnam (Berlin and New York, 1979), 22936.

— "The Prosecution of Homicide in Athens", GRBS 20.4 (1979) 301-23.

GERNET, Louis: "Observations sur la loi de Gortyne", in Droit et société dans la Grèce ancienne (New York, 1979; 1ª. ed.,1955).

Gould, John: "Law, Custom and Myth: Aspects of the Social Position of Women in Classical Athens", JHS 100 (1980) 38-59.

HANSEn, Mogens Herman: "The Prosecution of Homicide in Athens: a Reply", GRBS 22.1 (1981) 11-30.

HARRIS, Edward M.: "Did the Athenians regard Seduction as a worse Crime than Rape?", CQ 40 (1990) 370-377.

— "Review Article: Susan Deacy and Karen Pierce, eds. Rape in Antiquity: Sexual Violence in the Greek and Roman Worlds": EMC/CV XL, n.s. 16 (1997) 483-496. 
Harrison, A. R. W.: The Law of Athens. The Family and Property (Oxford, 1968).

- The Law of Athens. Procedure (Oxford, 1971).

HARrison, Thomas: "Herodotus and the Ancient Greek Idea of Rape", in Rape in Antiquity, eds. S. DeACY and K. F. Pierce (Great Britain, 1997), 185-208.

Humphreys, Sally: The Family, Women and Death (London, Boston, Melbourne and Henley, 1983).

HalPerin, David M., "The Democratic Body: Prostitution and Citizenship in Classical Athens", in One Hundred Years of Homosexuality (New York and London 1990) 88-112.

LAWLESS, John Martin, Law, argument and equity in the speeches of Isaeus (Ann Arbor, 1991).

MacDowell, Douglas: Athenian Homicide Law (Manchester, 1963).

— "Hybris in Athens", G\&R 23 (1976) 14-31.

- The Law in Classical Athens (New York, 1978).

— "The oikos in Athenian Law", CQ 39 (1989) 10-21.

MoLINER, María: Diccionario de uso del español (Madrid, 1984).

OGDEN, Daniel: "Rape, adultery and the protection of bloodlines in classical Athens", in Rape in Antiquity, eds. S. DEACY and K. F. PIERCE (Great Britain, 1997), 25-41.

PAOLI, Ugo Enrico: "Il reato di adulterio (moicheia) in diritto attico", SDHI 16 (1950) 123 -70 .

PARADISO, Annalisa: "Violenza sessuale, hybris e consenso nelle fonti greche", in Vicende $e$ figure femminili in Grecia e a Roma, a cura di R. RAFFAELLI (Ancona, 1995) 93-109.

SCHAPS, David: "The Women of Greece in Wartime", CP 77.3 (1982) 193-213.

SHLAIN, Leonard: El alfabeto contre la diosa. El conflicto entre la palabra y la imagen, el poder masculino y el poder femenino (Barcelona, 2000; $1^{\mathrm{a}}$ ed. 1998).

Soto PÉREz, Ricardo: Nociones de derecho positivo mexicano (29a. ed. México, 2000).

Thompson, Wesley E.: "Athenian Marriage Patterns: Remarriage", California Studies in Classical Antiquity 5 (1972) 211-25.

ToDD, S. C.: The Shape of Athenian Law (Oxford, 1993). 